\title{
HYPOTHESIS TESTING IN MEDICAL RESEARCH: A KEY STATISTICAL APPLICATION
}

\author{
Ashok Kumar
}

\begin{abstract}
"Hypothesis testing" is an integral and most important component of research methodology, in all researches, whether in medical sciences, social sciences or any such allied field. It is a guideline in planning, implementation and getting final results thereof, in undertaking any research work. The present paper, in this direction, is designed mainly as a key note, to highlight the basics towards hypothesis, testing its validity i.e. Acceptance "or" rejection and finally interpreting the tenability of selected variables as a solution to the postulated " research problem ". To supplement with, a few problem based illustrations (pbi)s have also been incorporated accordingly.
\end{abstract}

KEY WORDS: Hypothesis; Null Hypothesis; Probability Level; p- value; Research Hypothesis; Statistical significance

1. Associate Professor of Biostatistics, Department of Community Medicine, Universal College of Medical Sciences \&Teaching Hospital, Bhairahawa, Nepal

\section{For Correspondence}

Dr. Ashok Kumar

Associate Professor of Biostatistics,

Department of Community Medicine,

Universal College of Medical Sciences \& Teaching

Hospital, Bhairahawa, Nepal

E-mail: aku001@rediffmail.com 


\section{INTRODUCTION}

In its simplest form, "any formulation under known conditions", may be termed as a hypothesis; which, otherwise in the words of eminent researchers and social scientists is stated as (i) an assumption or supposition to be approved/ disapproved (ii) a formal question that tends to be resolved (iii) a necessary and most inevitable link between theory and the investigation ( i.e. An empirical finding ) leading to the discovery of additions to the scientific body of existing knowledge (iv) a formal statement in respect of expected relationship between the dependent and independent variables (v) a tentative generalization; the validity of which remains to be tested (vi) as a research hypothesis it is a predictive statement, which relates independent variable(s) to the dependent variable and that it is capable of being tested by scientific methods at desired probability levels.

While in terms of underlying characteristics a hypothesis must possess (1) it serves as a principal instrument in research (2) it is a tentative answer to a question (3) it is in a declarative form and specific in its approach and limited in scope (4) it is consistent with known facts and is based on some knowledge and previous researches (5) it is always subject to being tested for its validity (6) it always looks forward (7) it is clearly and precisely stated and has no ambiguity of any form (8) when accepted it results to be incorporated in the scientific body of knowledge, while on being rejected it clears the way for another one to be put forward (9) it enables a researcher to conclude what is true and what is false.

\section{ANALYTICAL FRAME WORK}

Like other application fields in medical sciences as well, the analytitical frame work in respect of testing of hypothesis comprises of 1 . formulating research hypothesis 2 . framing corresponding null hypothesis 3 . selecting appropriate test of significance and finally 4 . approving/disapproving research hypothesis on the basis of acceptance/rejection of null hypothesis.

1. The starting point, is framing a hypothesis as per objectives of the main theme of the research body, which is commonly known as a research hypothesis; likemedicine a cures the disease ' $d$ ' in a better way than medicine $b$; vaccinated persons are less prone to smallpox as compared to unvaccinated persons; high potency dose cures the disease more quickly as compared to a low potency dose; adoption of healthy life-style checks the diabetes mellitus and its ill effects more effectively; smoking is a cause of Lungs infection; students who take pre course orientation classes perform better in creativity to their research problem than those who do not take pre course orientation classes; persons living in urban areas have better access to high-tech medical facilities than those living in rural areas: high status persons are more susceptible to hive than low status persons.

2. After formulating the research hypothesis, the next step consists of making corresponding null hypothesis (a statistical hypothesis which (i) can be tested for its validity i.e. Acceptance/rejection and (ii) is more popularly known as a hypothesis of zero difference or no difference.

3. Thereafter, the next point of concern is selecting and using the most appropriate statistical test like the t-test, the z-test, the F-test, the chi-square test, for testing the statistical significance or in significace, of the observed result on the basis of acceptance/rejection of the null hypothesis; to find out as to whether the observed result is a real one "or" it is only due to some chance/error factor. This is decided by adopting any of the following methods, i.e. Method (i) or method (ii): Method (i) test statistic based method

If at a specified probability level (most commonly used 0.05 and 0.01 i.e. $5 \%$ and $1 \%$ levels of significance).

(a) Calculated test statistic ( $\mathrm{t} / \mathrm{z} / \mathrm{F} /$ chi-square) is less than the corresponding table value, then it is not significant and we can accept the null hypothesis.

(b) Calculated test statistic is equal to or greater than the corresponding table value, then it is significant and we shall reject the null hypothesis.

Method (ii) - p-value based method:

As per prevalent notions

(a) If the test statistic's corresponding p-value is greater than 0.05 ; then the observed result is statistically not significant.

(b) If the, $p$-value is less than 0.05 but greater than 0.01 , then the observed result is statistically significant.

(c) If the p-value is less than 0.01 , then the observed result is statistically highly significant. It is also most pertinent at this point to very clearly know that (i) t-test and z-test are mainly used to test the significance of difference between two means, two proportions, two correlation coefficients, two regression coefficients with the t-test being suitable for samples of small size ( less than 30 )and the z-test for samples of large size (at least 50 ) (ii) chisquare test is mainly used for testing the significance of difference between observed (experimental) and the expected(theoretical/hypothetical) frequencies and testing 
association between two attributes like vaccination and control of disease and that it is suitable for samples of large size ( at least 50 ) (iii) f-test is used for testing significance of difference between a number of means ( more than two) through analysis of variance (ANOVA) tables.

4. The last and the final step consist of deriving the final result in terms of validity/invalidity of research hypothesis leading towards accepance/rejection of postulated research theory.

As mentioned elsewhere- (a) the rejection of null hypothesis results to statistical significance of the observed result and therefore validating and declaring the research hypothesis as true. (b) The non rejection (acceptance) of null hypothesis indicates statistical insignificance of the observed result and therefore devalidating and declaring the research hypothesis as false.

\section{PROBLEM BASED ILLUSTRATIONS (PBI) s:}

To have still more clarity in respect of above, a few problem based illustrations (pbi) s are being presented in nut and shell, as under:

1) Problem: to find out whether medicine a is better than medicine $b$ Research hypothesis: medicine $a$ is better than medicine a. Null hypothesis: there is no difference in medicine $a$ and medicine $b$.

Result: the rejection of null hypothesis indicates a significant difference i.e. a real difference between the two medicines and therefore results to acceptance of research hypothesis, while the acceptance of null hypothesis indicates an insignificant Difference i.e. a difference only due to chance or error factor; and therefore it results to rejection of research hypothesis. (In this we can use the ttest or the z-test as per size of sample).

2) Problem: to find out whether vaccination against hepatitis $\mathrm{b}$ is effective in controlling hepatitis b. Research hypothesis: vaccination against hepatitis $b$ is effective in controlling hepatitis $b$. Null hypothesis: vaccination and hepatitis $b$ are independent of each other. Result: the rejection of null hypothesis results to effectiveness of vaccination in controlling hepatitis $b$ and therefore validates the research hypothesis; while its acceptance indicates ineffectiveness of vaccination in controlling hepatitis $b$ and therefore invalidates the research hypothesis. (This can be tested by chi-square test).

3) Problem: to find out, whether the proportion of disease affected persons in the experimental group is lower than that in the control group.

Research hypothesis: the proportion of disease affected persons in the experimental group is lower than that in the control group. Null hypothesis: there is no difference in the proportions of disease affected persons in the experimental and the control groups. Result: the rejection of null hypothesis shows a significant difference between the two proportions and therefore validates the research hypothesis to declare that proportion of disease affected persons in experimental group is lower than that in the control group; while its acceptance shows the difference of proportions as insignificant and hence results to rejection of the research hypothesis ( $t$ test or $\mathrm{z}$ test)

4) Problem: to find out whether, being on diet is associated with sex.

Research hypothesis: females are more adhesive to being on diet, as compared to males.

Null hypothesis: sex and being on diet, are independent of each other.

Result: the rejection of null hypothesis results to association between sex and being on diet and therefore validates the research hypothesis that females are more.

Adhesive to being on diet as compared to males, while its acceptance shows no association between sex and being on diet and results to rejection of research hypothesis. (this can be checked by chi-square test).

\section{CONCLUSION}

As a concluding remark of this key note, it may be pointed out that (i) a null hypothesis or in turn, a research hypothesis instead of being proved is always subject to be tested for its validity i.e. Acceptance or rejection towards its final approval or disapproval. (ii) It must be clear in respect of its approach, scope and the perspectives to which it corresponds and (iii) it maintains its unambiguity. 


\section{REFERENCES}

1. Goode WH, Hatt PK. Methods in Social Research: NewYork, Mc Graw Hill, 1952 PMCid:PMC2021723

2. Kapur JN, Saxena HC. Mathematical Statistics: S.Chand \& Co. New Delhi.

3. Maxwell JA. Quantitative Research Design: An Interactive Approach: New Delhi, Sage Publications, India Ltd.: 2005.

4. Mc Grath JH. Research Methods and Design for Education: Scranton, P.A. International Text book Company: 1970
5. Neuman WL. Social Research Methods: Quantitaive and Qualitative Approaches: New Delhi, Pearson Educations: 2006.

6. Pant PR. Social Science Research and Thesis Writing: Buddha Academic Publishers and Distributors Pvt. Ltd., Kathmandu, Nepal. 2012

7. Peters LD. Theory Testing In Social Research; The Marketing Review, 3(1) 65-82 2002.

http://dx.doi.org/10.1362/146934702321477235

8. Young PV, Schmid CF. Scientific Social Surveys on Research; New Delhi, Prentice and Hall of India; 1968.

\section{SUBSCRIPTION CHARGES}

\begin{tabular}{|c|c|c|}
\multicolumn{1}{c}{} & \multicolumn{1}{c}{$\begin{array}{r}\text { INSTITUTION } \\
\text { Single copy/Annual }\end{array}$} & $\begin{array}{l}\text { INDIVIDUAL } \\
\text { Single copy/Annual }\end{array}$ \\
\hline NEPAL & NRS. $300 / 1000$ & NRS. 200/700 \\
\hline SAARC COUNTRIES & IRS. 300/1000 & IRS.200/700 \\
\hline OTHER COUNTRIES & US\$ $40 / 100$ & US\$ 20/75 \\
\hline
\end{tabular}

ADVERTISEMENT CHARGES

\begin{tabular}{|c|c|c|}
\hline S.NO & PAGE & RATE (NC) \\
\hline 1. & FULL BACK COVER & 15000 \\
\hline 2. & FULL INSIDE OF FRONT COVER & 12000 \\
\hline 3. & FULL INSIDE & 10000 \\
\hline 4. & HALF SIDE & 8000 \\
\hline 5. & QUARTER & 4000 \\
\hline
\end{tabular}

